\title{
Computational Lock and Key and Dynamic Trajectory Analysis of Natural Biophors Against COVID-19 Spike Protein to Identify Effective Lead Molecules
}

\author{
Irfan Navabshan ${ }^{1} \cdot$ Balasubramaniyan Sakthivel $^{2} \cdot$ Rajesh Pandiyan $^{3} \cdot$ Mariya Gover Antoniraj $^{4}$. \\ Selvakumar Dharmaraj ${ }^{5}$. Veeramuthu Ashokkumar ${ }^{6,7} \cdot$ Kuan Shiong Khoo $^{8} \cdot \mathrm{Kit} \mathrm{Wayne} \mathrm{Chew}^{9}$. \\ Abimanyu Sugumaran ${ }^{10} \cdot$ Pau Loke Show ${ }^{8}$ (i)
}

Received: 17 March 2021 / Accepted: 13 June 2021 / Published online: 22 June 2021

(C) The Author(s), under exclusive licence to Springer Science+Business Media, LLC, part of Springer Nature 2021, corrected publication 2021

\begin{abstract}
New pandemic infection of coronaviridae family virus spread to more than 210 countries with total infection of 1,136,851 and 62,955 (4.6\%) deaths until 5th April 2020. Which stopped the regular cycle of humankind but the nature is consistently running. There is no micro molecule remedy found yet to restore the regular life of people. Hence, we decided to work on natural biophores against the COVID proteins. As a first step, major phytoconstituents of antiviral herbs like Leucas aspera, Morinda citrifolia, Azadirachta indica, Curcuma longa, Piper nigrum, Ocimum tenuiflorum, and Corallium rubrum collected and performed the lock and key analysis with major spike protein of COVID-19 to find the best fitting lead biophore using computational drug design platform. The results of protocol run showed, phytoconstituents of Morinda citrifolia and Leucas aspera were found lower binding energy range of -55.18 to $-25.34 \mathrm{kcal} / \mathrm{mol}$, respectively and compared with Hydroxychloroquine $(\mathrm{HCQ})(-24.29 \mathrm{kcal} / \mathrm{mol})$ and Remdesivir $(-25.38 \mathrm{kcal} / \mathrm{mol})$. The results conclude that, core skeletons chromen, anthracene 9, 11 dione and long-chain alkyl acids/ester-containing biophores showen high stable antagonistic affinity with S-protein. Which leads the breakdown of spike protein and ACE2 receptor complex formation and host mechanism of corono virus. In addition, the dynamic trajectory analysis confirmed the complete denaturation of spike protein by the molecule 4-(24-hydroxy-1-oxo-5-n-propyltetracosanyl)-phenol from Leucas aspera and stability of spike-ligand complex. These biophores will aid the researcher to fabricate new promising analogue and being recommended to assess its COVID-19 treatment.
\end{abstract}

Keywords COVID-19 · Spike Protein · In-silico method · Natural Biophors · Anthracene 9,11 dione · Dynamic simulation

\section{Introduction}

Since, December 2019, ' $n$ ' number of researchers running behind the ongoing Coronavirus disease-2019 (COVID19) pandemic. As, it reached more than 210 countries with approximately 100 million cases worldwide with approximately 2,214,023 of total death, 74 million peoples got recovered and 1 million of average daily new cases were identified by worldwide by January 2021 [1]. In many countries, the second wave of COVID-19 begins recently, and the

Abimanyu Sugumaran

abipharmastar@gmail.com

$\triangle$ Pau Loke Show

PauLoke.Show@nottingham.edu.my;

showpauloke@gmail.com

Extended author information available on the last page of the article post COVID complications are remains uncertain. The morbidity rate is uncontrollable irrespective of age and gender in many countries, especially in USA, Italy, France, UK, China, Iran and India. The reported mortality rate of SARS-CoV is about $15 \%$ initially and later $3.4 \%$ while comparing MERS$\mathrm{CoV}$ has $34.4 \%$ morbidity rate [2]. In addition, research laboratories all over the world have wound down or limited operations and panicking governments have promulgated policies that threatened the careers of immigrant researchers. One COVID-19 survey uncovered that close to a third of neuroscience researchers in Britain contemplated leaving their scientific discipline due to a lack of resources, personnel and ability to continue experimental work [3].

The structural virologist exposed the complete cycle of corona virus and they reported the COVID viral genome consists of more than 29,000 bases and encodes 29 proteins which is vital for the growth and spreading of COVID-19 
[4]. Specifically, Spike protein (S-Protein) binds to its receptor human ACE2 (hACE2) through its receptor-binding domain (RBD) and is proteolytically activated by human proteases which leads to invade the virus inside the host cells. This findings aid to find the inhibitors against the S-protein will be effective and promising target.

Taking account on present treatment, convalescent plasma therapy has greater potential $[5,6]$. Since, it could have the antibody against the specific viral load to fight against the COVID-19. However, the method is limited due to the various mutation of COVID-19 virus which manipulates different side effects. The accessible treatment methods are very limited due to the heavy viral load, type of mutation, and the current treatment scenario-focused towards only with symptomatic approaches. The hydroxychloroquine (HCQ), an antimalarial drug and azithromycin, a broad-spectrum antibiotic have used to treat COVID-19, which may cause severe side effects in many comorbid patients. Similarly, preliminary report of antiviral drug known as Remdesivir showed the better effect on COVID-19 and Food and Drug Administration (FDA) has recently approved it for the treatment. Besides, several countries confirmed that the recurrence of COVID-19 occurs in patients, which the scientists are more scrambled to protect $[7,8]$.

Various researchers are effectively occupied and trying to troubleshoot this issue, with the help of natural libraries. As our contribution, the Indian traditional medical system, such as Ayurveda can help to treat various viral diseases. Many of the viral diseases were treated with the combination of natural source of Azadirachta indica (Neem), Curucuma longa (Turmeric), Ocimum tenuiflorum (Holy Basil), Piper Nigrum (Pepper), Morinda tinctoria (Indian Mulberry), Corallium rubrum (Marine Red Coral Plant) and Leucas aspera (Thumbai). It has been reported that bark extract of Azadirachta indica has significant antiviral activity against the Herpes simplex virus type-1 (HSV-1), new castle disease and influenza virus $[9,10]$. Curcumin is the major active constituent of turmeric, which has wider pharmacological benefits including anticancer, antioxidant, antimicrobial and antiviral properties especially human respiratory syncytial virus (RSV) hepatitis B virus (HBV), hepatitis C virus $(\mathrm{HCV})$, noroviruses and arboviruses and lower respiratory infection [11, 12]. Ocimum tenuiflorum (Holy Basil) known as tulsi, will help to increase the helper T cells, natural killer cells (NK cells) that strengthen the immune system to defend against the viral infection. While, black pepper has great antioxidant, antimicrobial and antiviral properties [13].

Traditionally, Piper nigrum is used with turmeric to minimize the severe throat infection as well as, the absorption of curcumin drastically increased when consumed with pepper [14]. The fruit powder and leaves extract of Morinda citrifolia was reported against replication of HIV-1(IIIB) in MT-4 cells, HCV in Huh 5.2 cells and Hepatitis C Virus respectively [12]. Furthermore, Corallium is an active marine red coral plant, which could be used to treat severe upper respiratory and otorhinolaryngology infection, including dry cough [15]. Leucas aspera has reported analgesic, antipyretic, antirheumatic, anti-inflammatory, and antibacterial properties treatment by oral treatment [16]. The aerial parts of the Leucas aspera plant materials have reported possessing antioxidant and anti-bacterial properties [17]. Leucas aspera has also been verified for its viricidal activity such as anti-MCV (Mouse Corona Virus) and anti-HSV (Herpes Simplex Virus) activities [18].

Thus, we primly decided to study and screen the above said natural biophores against the spike protein target. To swift the work, we utilized the computational simulation tools such as structure-based drug design (Docking) and molecular dynamic simulation studies. Also, this study designed to expose atomic level investigation of interactions between spike proteins with bioactive compounds of selected medicinal plants. Eventually, the natural biphores energy scores are compared with hydroxychloroquine (HCQ) and Remdesivir. Nonetheless, the stability of the distinct spike protein and inhibitor docked protein complex was analyzed to study the promising inhibition by the lead molecule.

\section{Methodology}

\section{COVID-19 Spike Protein Preparation}

X-ray diffracted structure of novel coronavirus spike receptor-binding domain complexed with its receptor angiotensinconverting enzyme (ACE2) with the resolution of $2.50 \AA$ has taken from the PDB (6LZG) for this study. Initially, the structure was checked for missing amino acids and alternative confirmation and improved with the aid of clean protein protocol in BIOVIA Discovery studio. CHARMM (Chemistry at Harvard molecular mechanics) force field was applied, and the energy of protein was minimized to make the protein stable form using the smart minimizer algorithm (1000 steps of Steepest Descent, followed by Conjugate Gradient minimization) with RMS (Root mean square) gradient tolerance of 0.1 . After minimization, the binding site of the protein was defined using the two algorithm such as eraser and flood-filling algorithm to catch contiguous space residing of unoccupied, coupled grid points.

\section{Phytoconstituents Preparation}

Nighty eight phytoconstituents were collected from the herbs such as Azadirachta indica (Neem), Curucuma longa (Turmeric), Ocimum tenuiflorum (Holy Basil), Piper nigrum (Pepper), Morinda tinctoria (Indian Mulberry), Corallium rubrum (Marine Red Coral Plant), Leucas aspera (Thumbai) 
which are currently hypothesized effective against COVID19. The.sdfformate files of the phytoconstituents downloaded from the PubChem public domine and the CHARMM force field applied with Consistent Valence Forcefield (CVFF) partial charges. These forcefield typed molecules energy was converted to local minima using the smart minimizer algorithm with 5000 steps. Energy minimized molecules subjected to the docking process.

\section{CDOCKER Protocol and Interaction Analysis}

Docking module of CDOCKER in the BIOVIA discovery studio utilized to run the receptor-ligand interaction studies. The following protocol parameters (Table SI-1) were fixed in the CDOCKER window and run the algorithm to predict the binding affinities between the spike protein and natural phytoconstituents. This protocol run added the various energy values such as -CDOCKER INTERACTION ENERGY, -CDOCKER ENERGY, Angle Energy, Bond Energy, Solvation Free Energy, Urey-Bradley Energy, Van der Waals Energy, Dihedral Energy, Electrostatic Energy and Hydrogen Bond Energy [19, 20]. After the completion of the docking process, the results of the docked pose were analyzed with the aid of view interaction tool. Eventually, the results and amino acid interactions were analyzed and discussed to identify effective phytoconstituents. Interaction pattern was distinguished by different colors as shown in Table SI-2.

\section{Molecular Dynamic Simulation and Trajectory Analysis}

The physical movement of atoms at nanosecond (ns) time duration was analyzed by using this computer simulation method and the trajectories also analyzed for binding and nonbinding macromolecule. Standard dynamic cascade protocol (5 step) in BIOVIA discovery studio V 17.0 was used to study the nature of S-Protein and the best docked complex. It instigates with 2000 steps of Adopted Bassis NR and 1000 steps of Steepest Descent minimization with 0.1 RMS gradient cutoff. Further, $0.1 \mathrm{~ns}$ heating simulation was carried out with 2 fs time steps with 50 adjusted velocity frequency. This minimized and temperature determined input S-Protein and docked protein was submitted to equilibration step with same parameters as heating. Finally, the production step was achieved at $0.4 \mathrm{~ns}$ level with NVT condition and electrostatic energies was calculated by spherical cutoff method. Root Mean Square Deviation (RMSD) of confirmation, Root Mean Square Fluctuation (RMSF) of residues and protein Torsion Angles of the residues was examined using the analyze trajectory protocol. Total energies of each confirmation in each time frame of protein and docked protein was calculated and compared to identify the stability of docked complex.

\section{Results and Discussion}

\section{Spike Protein Targeted Approaches}

Coronavirus is static in nature; it spreads through various carriers and invades the human cells through receptor recognition [21]. The COVID-19 protein envelope has homo trimeric spike glycoprotein (S protein), which senses the receptor in the host cell [22]. The receptor-binding domain of subunit-S1 of spike protein, directly networks with the human cell membrane receptor [23]. While, subunit S2 enables the fusion and enter of virus-cell. ACE2 was one of the proteins responding to the spike protein to mediate COVID conquering human cells. Thus, blocking this complex formation will be possible to prevent the invasion of the host cell, and growth division of COVID-19 leads to eradication of infection [22]. The major phytoconstituents, interacted with spike protein to identify the affinity, and compared with HCQ and Remdesivir drug interactions. A binding cavity identified between the spike protein and the ACE2 protein using the eraser algorithm and flood-filling algorithm. This algorithm identified the coordinates of X: $-34.18992 \mathrm{Y}$ : 26.050559 and Z: 4.772892 with a radius of $9.90 \AA$ (see Fig. 1a). Binding the drug molecules lead to the denaturing of the complex and inactivation.

\section{Hydroxychloroquine and Remdesivir}

HCQ (Fig. SI-1a) is an antimalarial class of drug used to combat autoimmune diseases, which contain the basic chlorine substituted quinolone core skeleton extended with the bulky chain. The present work performed the interaction between the HCQ and spike protein. The results of this study showed that the HCQ CDOCKER energy of - $24.2987 \mathrm{kcal} /$ mol. Interaction pattern analysis showed that the HCQ formed interaction with the protein through three favorable interactions such as conventional hydrogen bond, carbonhydrogen bond, $\pi$-Alkyl and one donor unfavorable interaction. HCQ formed bonds with the spike binding domain amino acids in the following manner (Fig. SI-2).

Three hydrogens of ethanolic group of HCQ formed a network with oxygen atom of $\mathrm{His}_{34}$ amino acid, $\mathrm{O}_{2}$ of $\mathrm{Glu}_{37}$ generates conventional hydrogen bond with the $\mathrm{H}_{49}$ of the $\mathrm{HCQ}$. Hydrogen $\mathrm{HZ}_{2}$ atoms of the $\mathrm{Lys}_{353}$ interact with the oxygen $\left(\mathrm{O}_{2}\right)$ of HCQ. In the meantime, the phenolic $\mathrm{OH}$ group of $\mathrm{Tyr}_{505}$ unfavored the binding by forming a repulsive force with the $\mathrm{H}_{49}$ atom of HCQ. Similarly, Quinoline ring of HCQ formed $\pi$-Alkyl interaction with C-Y o fLys ${ }_{417}$ 


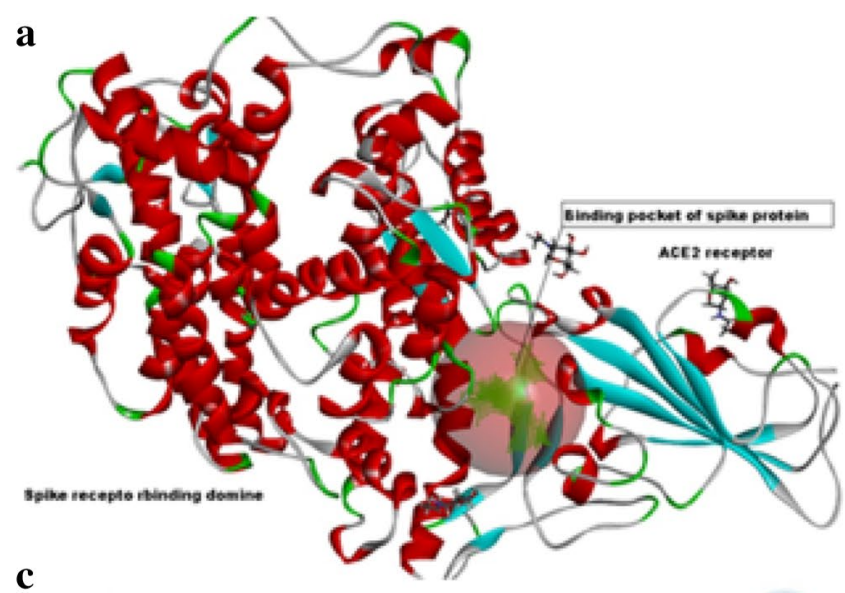

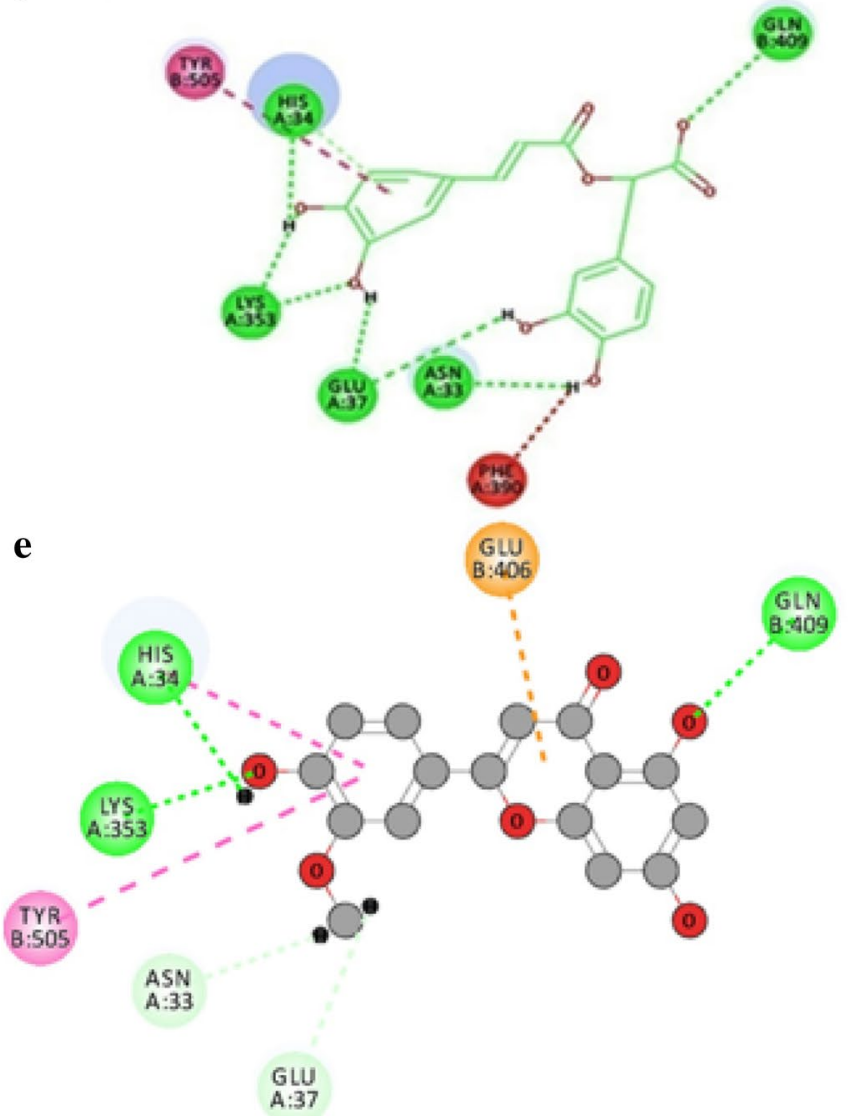

b
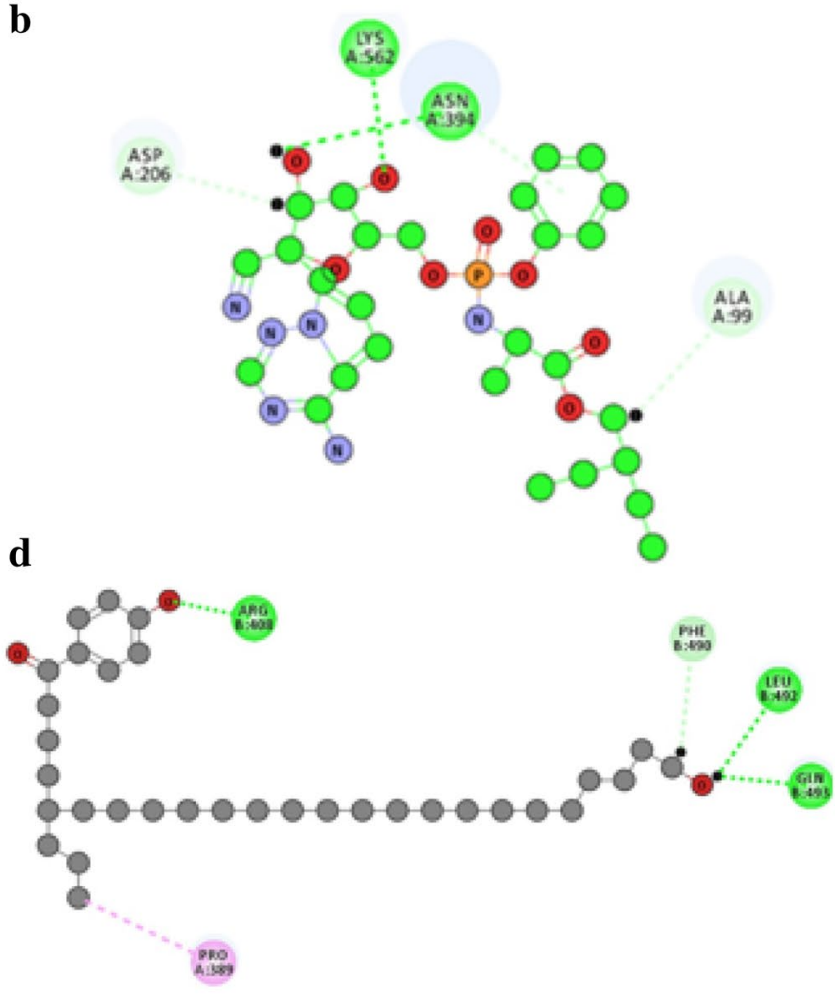

f

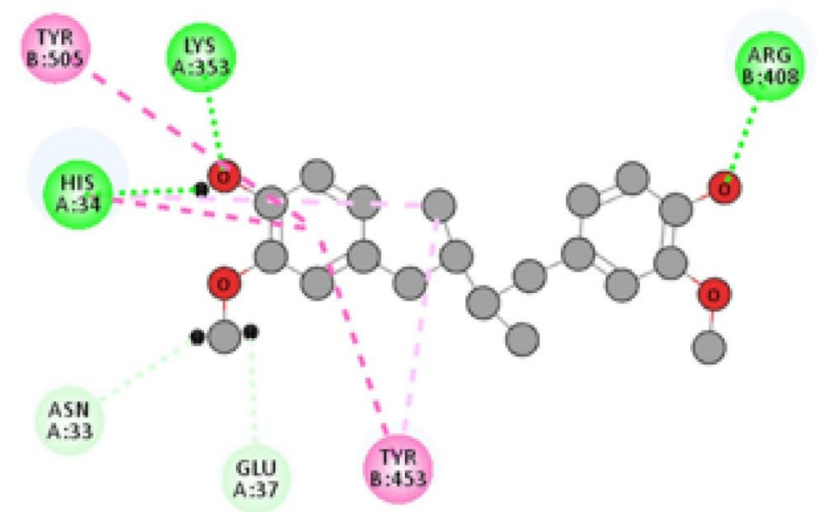

Fig. 1 a Secondary structure of S-Protein with binding site b Redimsivir c Rosemeric acid d 4-(24-hydroxy-1-oxo-5-n-propyltetracosanyl)-phenol $\mathbf{e}$ chrysoeriol $\mathbf{f}$ dihydro guaiaretic acid

amino acid of ACE2 receptor and oxygen $\left(\mathrm{O}_{2}\right)$ atom of Glu406 interacted with fourth amino hydrogen.

Remdesivir (Fig. SI-1b) is a nucleotide drug that distracts viral replication, initially evaluated for Ebola outbreak clinical trials. The ability of Remdesivir to inhibit coronavirus replication including SARS-CoV-2 was demonstrated following evaluation at numerous laboratories of virology (Sun 2020). The present work was performed, the interaction between the remdesivir and spike protein (Fig. 1b).
Remdesivir contains triazin and furan ring, which help to form hydrogen bond with the Asn394 and Lys562 causes the well bind inside the binding site of spike protein. Other two carbon-hydrogen bonds created between Asp206 and furan carbon, adjacent carbon of ester group and Ala99 amino acid leads the better orientation fix of the drug (Fig. SI-3).

This overall effect yields the breakdown of recognition and response complex formation leads to inhibition of the multiplication of COVID-19 virus in the host cell. 
The potential interaction energy between spike protein of COVID-19, HCQ, Remdesivir and all identified lead phytoconstituents were summarized in Table 1 . Interaction energy between spike protein of COVID-19, of all selected 98 phytoconstituents of seven herbs, Remdesivir and HCQ were reported in Table SI-3.

\section{Azadirachta indica (Neem)}

The major phytoconstituents of Azadirachta indica have docked with the spike protein. Amongst the 10 phytoconstituents, significant five compounds (i.e., 6-desacetyl lnimbinene, Beta-sitosterol, Isomeldenin, Nimocinol, and Quercetin) generate the proper pose inside the binding pocket of the spike protein. The above interactions of quercetin shown a significant CDOCKER affinity of $-35.755 \mathrm{kcal} /$ mol than the HCQ $(24.299 \mathrm{kcal} / \mathrm{mol})$. It produced five different kinds of interaction with active site amino acids. Three oxygen atoms of the quercetin formed four conventional hydrogen bonds with $\mathrm{Gln}_{409}, \mathrm{Lys}_{417}, \mathrm{Glu}_{406}$, and $\mathrm{Lys}_{353}$. $\Pi$-lonepair, $\pi-\pi \mathrm{T}$ shaped interaction with $\mathrm{Tyr}_{453}, \mathrm{Tyr}_{505}$ made the quercetin as a higher affinity molecule than other (Fig. SI-4).

\section{Curcuma longa (Turmeric)}

The activity of Curcuma longa against the COVID-19, 44 bioactive compounds interacted with the spike protein. The results of the dock protocol run showed that the 44 bioactive compounds docked inside the active sites pace between the spike COVID protein and the host response protein $\mathrm{ACE}_{2}$. Amongst 44 bioactive compounds, remarkably 2 chemical entities such as benzene-2-methyl-1_4-bis (1-methylethyl) and Thymol have a higher dock score of -30.173 and -27.514 , respectively when compared with HCQ and Remdesivir. Hydrophobic nature of the compound benzene2-methyl-1_4-bis (1-methylethyl) formed carbon-carbon bond with $\mathrm{His}_{34}$ and three $\pi$-interaction with tyramino acid (Fig. SI-5).

\section{Piper nigrum (Pepper)}

The interaction analysis has performed on 12 major phytocompounds of Piper nigrum. Among, 10 phytoconstituents docked inside the binding site of the protein with less affinity compared with HCQ. The molecule alkamides showed an affinity of $-20.379 \mathrm{kcal} / \mathrm{mol}$ due to the forming two

Table 1 Energy between lead phytoconstituents, HCQ, Remdesivir and the spike protein (minimization and docking)

\begin{tabular}{|c|c|c|c|c|c|c|c|}
\hline Name & Int.Pot.* energy & Final.Pot. energy & Int.RMS $* *$ gradient & $\begin{array}{l}\text { Final RMS } \\
\text { gradient }\end{array}$ & $\mathrm{VdW} * * *$ energy & CDOCKER energy & $\begin{array}{l}\text { CDOCKER } \\
\text { interaction } \\
\text { energy }\end{array}$ \\
\hline Hydroxychloroquine & 119.143 & 12.424 & 40.857 & 0.009 & 3.366 & -24.298 & -50.285 \\
\hline Remdesivir & $1,033.230$ & -59.947 & 64.188 & 0.096 & -6.772 & -25.379 & 48.840 \\
\hline \multicolumn{8}{|l|}{ Azadirachta indica (Neem) } \\
\hline Quercetin & 71.982 & -6.859 & 42.9541 & 0.009 & 1.697 & -35.754 & -40.443 \\
\hline \multicolumn{8}{|c|}{ Ocimum tenuiflorum (Holy Basil) } \\
\hline Rosmarinic_acid & 24.244 & -67.214 & 39.0438 & 0.009 & -0.427 & -47.189 & -44.47 \\
\hline \multicolumn{8}{|c|}{ Morinda citrifolia (Indian Mulberry) } \\
\hline Soranjidiol & 32.527 & 2.527 & 41.355 & 0.006 & 5.534 & -29.099 & -33.569 \\
\hline Rubiadin & 46.342 & 13.394 & 42.818 & 0.008 & 6.463 & -29.116 & -34.798 \\
\hline Anthragallol & 26.246 & -7.936 & 43.332 & 0.008 & 3.767 & -29.322 & -30.905 \\
\hline Nordamnacanthal & 98.171 & 51.501 & 49.208 & 0.010 & 8.590 & -30.237 & -40.305 \\
\hline \multicolumn{8}{|l|}{ Leucas aspera (Thumbai) } \\
\hline Acacetin & 12.430 & 11.876 & 1.7505 & 0.009 & 3.344 & -30.498 & -37.842 \\
\hline Amyl_propionate & -15.109 & -16.510 & 1.569 & 0.009 & -2.805 & -31.699 & -30.704 \\
\hline Apigenin & 8.786 & 7.564 & 2.089 & 0.009 & 2.596 & -32.444 & -37.742 \\
\hline Oleic_acid & 7.450 & 5.229 & 1.013 & 0.008 & -8.627 & -33.233 & -46.728 \\
\hline $\begin{array}{l}\text { Nordihydroguaiaretic_ } \\
\text { acid }\end{array}$ & -3.957 & -10.108 & 1.231 & 0.009 & -1.920 & -33.527 & -45.013 \\
\hline Chrysoeriol & 11.586 & 8.096 & 2.229 & 0.009 & 2.714 & -33.944 & -40.873 \\
\hline $\begin{array}{l}\text { 4-(24-hydroxy-1-oxo-5- } \\
\text { n-propyltetracosanyl)- } \\
\text { phenol }\end{array}$ & 13.846 & 4.054 & 1.034 & 0.198 & -13.753 & -55.185 & -69.479 \\
\hline
\end{tabular}

*Initial Potential

**Intial Root Mean Square

***van der Waals 
conventional hydrogen bonds with the $\mathrm{Lys}_{417}$ and $\mathrm{Gln}_{409}$, which has lesser than the HCQ and Remdesivir (Fig. SI-6).

\section{Ocimum tenuiflorum (Holy Basil)}

Theoretical studies to explain the possible prevention activity against the COVID-19 showed that the 8 phytocompounds formed favored configurations inside the binding site. Among the eight compounds, Carvacrol and Rosmarinic acid showed higher binding possibilities with the energy of -26.682 and $-47.189 \mathrm{kcal} / \mathrm{mol}$ compared to HCQ and Remdesivir. Specifically, Rosmarinic acid formed seven conventional hydrogen bonds with 5 amino acids of $\mathrm{His}_{34}, \mathrm{Lys}_{353}, \mathrm{Glu}_{37}, \mathrm{Asn}_{33}$ and $\mathrm{Gln}_{409}$ also increased the affinity. In addition, $\pi$-donor hydrogen between $\mathrm{Tyr}_{505}$ boosts the binding with bioactive compounds. However, one of the catechol ring -OH hydrogen from the clash with $\mathrm{Phe}_{390}$ amino acid leads to unfavored the binding of Rosmarinic acid (Fig. 1c and Fig. SI-7).

\section{Corallium rubrum (Redcoral)}

Remarkably two significant phytocompounds from red coral are canthaxanthin and astaxanthin, which produce the red color of the corallium. The docking studies of the phytoconstituents revealed less activity in the spike's protein of COVID-19 with the high energy of $+63.512 \mathrm{kcal} / \mathrm{mol}$. These compounds are formed alkyl, and $\pi$-Alkyl interactions lead to less binding activity (Fig. SI-8).

\section{Morinda citrifolia (Indian Mulberry)}

About 13 phytocompounds of Morinda citrifolia have taken and docked with the spike protein domain of the COVID19. The results revealed that the 11 constituents of Morinda citrifolia formed good orientation inside the binding space of the spike protein. Among those phytoconstituents $5 \mathrm{~mol}-$ ecules such as Soranjidiol, Rubiadin, Anthragallol, Nordamnacanthal, and Quercetin show significant CDOCKER energies than HCQ. Precisely, Quercetin formed 4 conventional hydrogen bonds and $3 \pi$ types of interactions. As next Nordamnacanthal showed the $-30.236 \mathrm{kcal} / \mathrm{mo}$ linteraction affinity due to the formation of a conventional hydrogen bond with four amino acids of $\mathrm{His}_{34}, \mathrm{Lys}_{353}, \mathrm{Gly}_{496}$, and $\operatorname{Arg}_{403}$ formed hydrogen bond interaction with the hydroxyl and ketone $(\mathrm{C}=\mathrm{O})$ groups of the Nordamnacanthal. In addition, Aromatictri cyclic ring system of the molecules produced a $T$-shaped $\pi$ - interaction and $\pi$ donor hydrogen bond with $\mathrm{Tyr}_{505}$ and $\mathrm{His}_{34}$. Similarly, other 3 bioactive compounds formed multiple interactions, then the HCQ and Remdesivir drug molecules (Fig. SI-9).

\section{Leucas aspera (Thumbai)}

About 20 important bioactive compounds of Leucas aspera subjected to CDOCKER protocol which uses the CHARMM based algorithm resulted in the 17 phytoconstituents getting generated proper confirmation inside the chemical space of the binding site of spike protein domain. A molecule 4-(24-hydroxy-1-oxo-5-n-propyltetracosanyl)phenol (Fig. 1d) showed one-fold higher binding affinity $(-55.185 \mathrm{kcal} / \mathrm{mol})$ than HCQ. The affinity developed due to the complete penetration inside the cavity of this molecule in the space of the spike protein domain and response protein. This could make possible to prevent the formation of protein-protein complex. This molecule made the significant configuration in the chemical space of spike protein binding site with the aid of conventional hydrogen bond of $\operatorname{Arg}_{408}$, $\mathrm{Leu}_{492}, \mathrm{Gln}_{493}, 1$ carbon hydrogen bond with $\mathrm{Phe}_{490}$ and one Alkyl bond with amino acid Pro $_{389}$ (Fig. SI-10). Other six phytoconstituents formed better interaction inside the binding site of spike protein with the binding range of -33.945 to $-30.498 \mathrm{kcal} / \mathrm{mol}$ (Fig. 1e and f).

\section{Core Scaffolds Examination of High-Affinity Phytoconstituents}

Based on the theoretical and docking analysis of bioactive compounds of selected medicinal plants with the spike protein revealed that the following constituents might be the potent lead molecules to treat COVID-19 infection.

Structural analysis of these 13 molecules (Table 2) shown that the following three basic skeletons are important for the activity against the spike protein.(i.e., chromen, anthracene-9,10-dione) (Fig. 2a and Fig SI-11) ring skeleton and long alkyl chain acids/esters group. Chromen rings containing compounds formed most of $\pi$-anionic interaction with the Glutamine amino acids which enhance the affinity and modify the conformational changes of spike protein domain. Anthracene-9,10-dione tricyclic ring fragment made multiple $\pi$-type interaction such as $\pi-\pi$ stacked, $\pi-\pi$ T-shaped, $\pi$-alkyl and $\pi$-donor Hydrogen bond with tyrosine benzene ring and imine ring of histidine due to its extension of steric cloud property. Hydroxyl groups (-OH), ketogenic groups $(\mathrm{C}=\mathrm{O})$ substituted in the ring system sharing their electron to form the various conventional and carbon-hydrogen bonds. Long alkyl chain $\mathrm{C}_{4}-\mathrm{C}_{10}$ responsible for the binding of molecules in the hydrophobic tunnel between the recognition and response domain of spike protein (Fig. $2 b$ and Fig. SI-12). - $\mathrm{COOH}$, - $\mathrm{OH}$ and - $\mathrm{COO}$ group substituted tail parts of the alkyl chain increase the binding affinity of the ligand causes the modification of chemical nature of both the protein and increase the energy of protein, which leads to the destabilization of complex formation. 
Table 2 High affinity of the phytoconstituents from the selected medicinal plants<smiles>O=c1c(O)c(-c2ccc(O)c(O)c2)oc2cc(O)cc(O)c12</smiles>

Quercetin<smiles>CC1=C(O)C2C(=O)c3ccc(O)cc3C(=O)C2C=C1</smiles>

Soranjidiol<smiles>O=C1c2ccccc2C(=O)c2c1cc(O)c(O)c2O</smiles>

Anthragallol<smiles>COc1ccc(-c2cc(=O)c3c(O)cc(O)cc3o2)cc1</smiles>

Acacetin<smiles>O=c1cc(-c2ccc(O)cc2)oc2cc(O)cc(O)c12</smiles><smiles>O=C(/C=C/c1ccc(O)c(O)c1)OC(Cc1ccc(O)c(O)c1)C(=O)O</smiles>

Rosmarinic acid<smiles>Cc1c(O)cc2c(c1O)C(=O)c1ccccc1C2=O</smiles>

Rubiadin<smiles>Cc1c(O)cc2c(c1O)C(=O)c1ccccc1C2=O</smiles>

Nordamnacanthal<smiles>CCCCCOC(=O)CC</smiles>

Pentyl propionate<smiles>CCCCCCCCCCCCCCCCCCCC(=O)O</smiles>

Oleic acid

Apigenin 
Table 2 (continued)<smiles>C[C@H](Cc1ccc(O)c(O)c1)[C@H](C)Cc1ccc(O)c(O)c1</smiles><smiles>COc1cc(-c2cc(=O)c3c(O)cc(O)cc3o2)ccc1O</smiles>

Nordihydro guaiaretic acid

Chrysoeriol

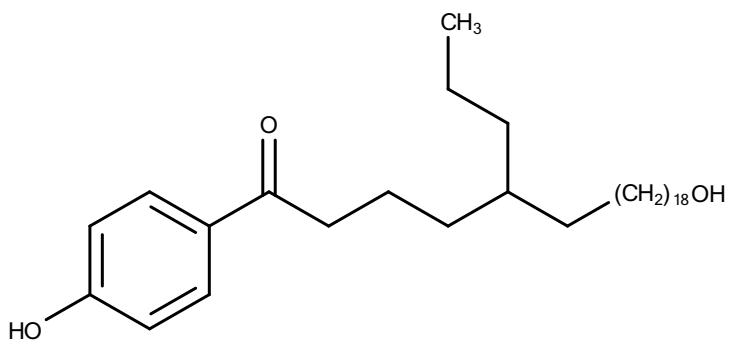

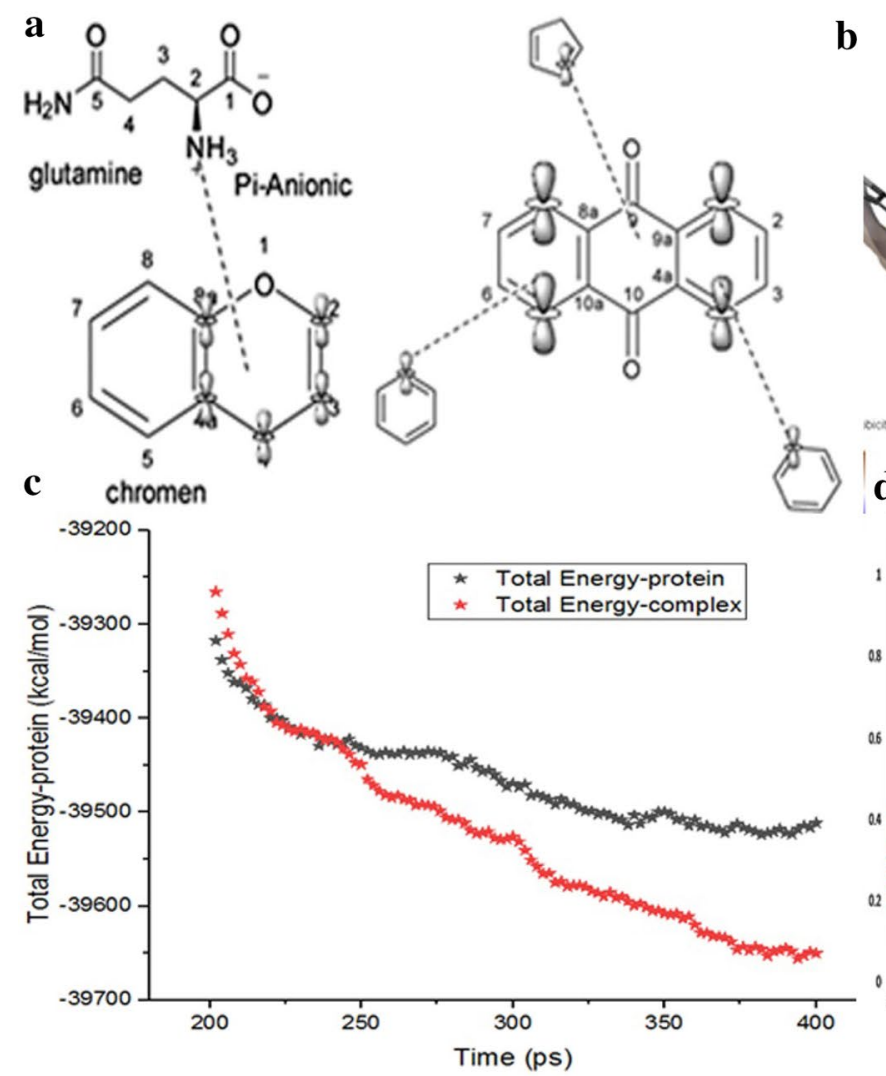

Fig. 2 a Chromen moiety and anthracene 9,11 dione moiety core skeletons of high-affinity molecules and the irinteractions with the active site amino acids of spike COVID-19 protein. b Hydrophobic tunnel cavity of S-Protein. $\mathbf{c}$ The total energy changes at the different b

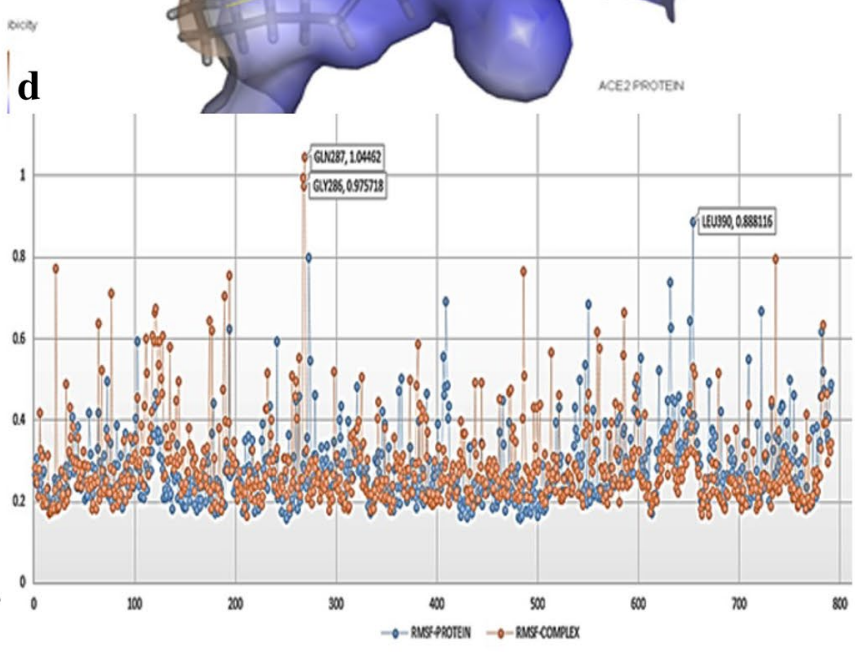

time interval for the spike protein (red) and the docked complex. d Total energy changes of residues of protein (blue) and docked protein complex (orange) 


\section{Standard Dynamic Simulation}

The standard dynamic simulation protocol run result of protein and docked complex studies showed that the energy and RMS gradient variations. The potential energy in the production step for the protein and the complex was found to be $-48,706.683 \mathrm{kcal} / \mathrm{mol}$ and $-48,753.865 \mathrm{kcal} / \mathrm{mol} \mathrm{respec}-$ tively (Table SI-4). The energy difference between protein and drug complex was negligible which proved the drug complex was stable to inhibit the protein completely. Total energy of Spike protein begins from - 39,317.4 kcal/mol at the beginning time, further it reduced to the local minima with the energy level of $-39,524.1 \mathrm{kcal} / \mathrm{mol}$ at the time of 382 ps time. Similarly, final energy of drug complex was found to be $-39,507.8 \mathrm{kcal} / \mathrm{mol}$ (Fig. 2c and Fig. SI-13).

\section{Trajectory Analysis}

The result of trajectory analysis protocol run added the RMSD and RMSF values for the 100 confirmation of protein and protein drug complex. The overlay graph revealed that the drug stably interacted and not made any energy changes of residues of the protein (Fig. SI-14). Drug molecules alter the confirmation two non-binding site amino acids of $\mathrm{Gly}_{286}$ and $\mathrm{Gln}_{287}$ (Fig. 2d and Fig. SI-15). Which not mark any fluctuations of any other residues of the protein confirmed the stability of the complex. These comparison between s-protein and docked s-protein complex proved that the complete stable inhibition by the lead molecule.

\section{Conclusion}

In this crucial time, Computational Interaction Analysis plays a significant role in identifying and developing a potent lead molecule for COVID-19. In this study we performed docking interaction of spike protein with seven medical herbs (Curcuma longa, Piper nigrum, Ocimum tenuiflorum, Corallium rubrum, Morinda citrifolia, Leucas aspera) The results of interaction analysis with spike protein exhibit the chromone, anthracene 9,11 dione and long-chain alkyl-substituted ester/acidic group contained biophors possessed significantly higher active than the HCQ and Remdesivir. These scaffolds fabricate the multiple hydrogen bonds and $\pi$-networks with active site amino acids of the spike protein. Based on the study results, most of the phytoconstituents of Leucas aspera and Morinda citrifolia showed greatest activity than HCQ and Remdesivir against COVID-19. This overall dynamic-trajectory simulation analysis concludes the lead molecule form stable complex with the S-protein and potential to completely inhibit the binding of virus into the host. This finding open ups the new way for the development of similar analogs and similar known drugs for repurposing intended to treat COVID-19.

\section{Future Phases}

Natural products could be the library of core skeletons and fragments of many unexplored drug molecules. The future direction of the study is to develop an effective drug molecule for the treatment of COVID-19 by isolating such potent phytocostituents or synthesis of the new drug molecule similar to these potent natural biophores. Also, the further study of preclinical and clinical evaluation using these isolated or developed molecules could help to deliver the evidence-based medicine against the COVID-19. In the part of vaccination, dozens of vaccine candidates are being under research. The mutation of the virus is major milestone in the vaccination development.

Supplementary Information The online version contains supplementary material available at https://doi.org/10.1007/s12033-021-00358-z.

Acknowledgements The authors are thanking full to SRM College of Pharmacy, SRM Institute of Science and Technology, Kattankulathur, B.S. Abdur Rahman Crescent Institute of Science and Technology, Chennai, National Centre for Coastal Research (NCCR), Chennai and Karpagam Academy of Higher Education, Coimbatore and Alagappa University, Karaikudi-630003, India.

Author Contributions Conceptualization, study designed and planned by Dr. AS. The methodology and study executed by Dr. IN, and Dr. BS. The data gathered reviewed and edited by Dr. RP, Dr. MGA, Dr SD Dr. VA, Dr. KSK, Dr KWC and Professor Dr. PLS. All the authors are equally contributed to write the manuscript here if the journal requires them.

Funding This research did not receive any specific Grant from funding agencies in the public, commercial, or not-for-profit sectors.

\section{Declarations}

Conflict of interest The authors report no conflict of interest.

\section{References}

1. Kristian, G., Andersen, A., Lipkin, I., Holmes, E., \& Garry, R. (2020). The proximal origin of SARS-CoV-2. Nature Medicine, 26, 450-455.

2. Ye, Z.-W., Yuan, S., Yuen, K.-S., Fung, S.-Y., Chan, C.-P., \& Jin, D.-Y. (2020). Zoonotic origins of human coronaviruses. International Journal of Biological Sciences, 16, 1686.

3. Raoult, D., Zumla, A., Locatelli, F., Ippolito, G., \& Kroemer, G. (2020). Coronavirus infections: Epidemiological, clinical and immunological features and hypotheses. Cell Stress, 4, 66.

4. Joynt, G. M., \& Wu, W. K. (2020). Understanding COVID-19: What does viral RNA load really mean? . The Lancet Infectious Diseases, 20, 635-636.

5. Duan, K., Liu, B., Li, C., Zhang, H., Yu, T., Qu, J., Zhou, M., Chen, L., Meng, S., \& Hu, Y. (2020). Effectiveness of convalescent plasma therapy in severe COVID-19 patients. Proceedings of the National Academy of Sciences, 117, 9490-9496.

6. Ou, J., Zhou, Z., Dai, R., Zhang, J., Lan, W., Zhao, S., Wu, J., Seto, D., Cui, L., Zhang, G., \& Zhang, Q. (2020). Emergence of 
RBD mutations in circulating SARS-CoV-2 strains enhancing the structural stability and human ACE2 receptor affinity of the spike protein. BioRxiv.

7. Beigel, J. H., Tomashek, K. M., Dodd, L. E., Mehta, A. K., Zingman, B. S., Kalil, A. C., Hohmann, E., Chu, H. Y., Luetkemeyer, A., Kline, S., \& Lopez de Castilla, D. (2020). Remdesivir for the treatment of Covid-19-preliminary report. New England Journal of Medicine.

8. Sun, D. (2020). Remdesivir for treatment of COVID-19: Combination of pulmonary and IV administration may offer aditional benefit. American Association of Pharmaceutical Scientists Journal, 22, 1-6.

9. Ahmad, A., Javed, M. R., Rao, A. Q., \& Husnain, T. (2016). Designing and screening of universal drug from neem (Azadirachta indica) and standard drug chemicals against influenza virus nucleoprotein. BMC Complementary and Alternative Medicine, 16, 1-8.

10. Petrera, E. (2015). Antiviral and immunomodulatory properties of Meliaceae family. Journal of Biologically Active Products from Nature, 5, 241-254.

11. Praditya, D., Kirchhoff, L., Brüning, J., Rachmawati, H., Steinmann, J., \& Steinmann, E. (2019). Anti-infective properties of the golden spice curcumin. Frontiers in Microbiology, 10, 912.

12. Ratnoglik, S. L., Aoki, C., Sudarmono, P., Komoto, M., Deng, L., Shoji, I., Fuchino, H., Kawahara, N., \& Hotta, H. (2014). Antiviral activity of extracts from Morinda citrifolia leaves and chlorophyll catabolites, pheophorbide a and pyropheophorbide a, against hepatitis C virus. Microbiology and Immunology, 58, 188-194.

13. Mondal, S., Varma, S., Bamola, V. D., Naik, S. N., Mirdha, B. R., Padhi, M. M., Mehta, N., \& Mahapatra, S. C. (2011). Doubleblinded randomized controlled trial for immunomodulatory effects of Tulsi (Ocimum sanctum Linn.) leaf extract on healthy volunteers. Journal of Ethnopharmacology, 136, 452-456.

14. Abou-Elkhair, R., Ahmed, H., \& Selim, S. (2014). Effects of black pepper (Piper nigrum), turmeric powder (Curcuma longa) and coriander seeds (Coriandrum sativum) and their combinations as feed additives on growth performance, carcass traits, some blood parameters and humoral immune response of broiler chickens. Asian-Australasian Journal of Animal Sciences, 27, 847.

15. Abou El-Ezz, R. F., Ahmed, S. A., Radwan, M. M., Ayoub, N. A., Afifi, M. S., Ross, S. A., Szymanski, P. T., Fahmy, H., \& Khalifa,
S. I. (2013). Bioactive cembranoids from the Red Sea soft coral Sarcophyton glaucum. Tetrahedron Letters, 54, 989-992.

16. Rahman, M. A., \& Islam, M. S. (2013). Antioxidant, antibacterial and cytotoxic effects of the phytochemicals of whole Leucas aspera extract. Asian Pacific Journal of Tropical Biomedicine, 3, 273-279.

17. Chew, A. L., Jessica, J. J. A., \& Sasidharan, S. (2012). Antioxidant and antibacterial activity of different parts of Leucas aspera. Asian Pacific Journal of Tropical Biomedicine, 2, 176-180.

18. Vimalanathan, S., Ignacimuthu, S., \& Hudson, J. (2009). Medicinal plants of Tamil Nadu (Southern India) are a rich source of antiviral activities. Pharmaceutical Biology, 47, 422-429.

19. Balasubramaniyan, S., Irfan, N., Umamaheswari, A., \& Puratchikody, A. (2018). Design and virtual screening of novel fluoroquinolone analogs as effective mutant DNA GyrA inhibitors against urinary tract infection-causing fluoroquinolone resistant Escherichia coli. RSC Advances, 8, 23629-23647.

20. Hall, D. C., Jr., \& Ji, H.-F. (2020). A search for medications to treat COVID-19 via in silico molecular docking models of the SARS-CoV-2 spike glycoprotein and 3CL protease. Travel Medicine and Infectious Disease, 35, 101646.

21. Lu, R., Zhao, X., Li, J., Niu, P., Yang, B., Wu, H., Wang, W., Song, H., Huang, B., \& Zhu, N. (2020). Genomic characterisation and epidemiology of 2019 novel coronavirus: Implications for virus origins and receptor binding. The lancet, 395, 565-574.

22. Vellingiri, B., Jayaramayya, K., Iyer, M., Narayanasamy, A., Govindasamy, V., Giridharan, B., Ganesan, S., Venugopal, A., Venkatesan, D., \& Ganesan, H. (2020). COVID-19: A promising cure for the global panic. Science of the Total Environment, 725, 138277.

23. Tang, T., Bidon, M., Jaimes, J. A., Whittaker, G. R., \& Daniel, S. (2020). Coronavirus membrane fusion mechanism offers a potential target for antiviral development. Antiviral Research, $178,104792$.

Publisher's Note Springer Nature remains neutral with regard to jurisdictional claims in published maps and institutional affiliations.

\section{Authors and Affiliations}

\section{Irfan Navabshan ${ }^{1}$. Balasubramaniyan Sakthivel ${ }^{2} \cdot$ Rajesh Pandiyan $^{3} \cdot$ Mariya Gover Antoniraj $^{4}$. Selvakumar Dharmaraj ${ }^{5}$. Veeramuthu Ashokkumar ${ }^{6,7} \cdot$ Kuan Shiong Khoo $^{8} \cdot$ Kit Wayne Chew $^{9}$. Abimanyu Sugumaran ${ }^{10}$. Pau Loke Show ${ }^{8}$ (i)}

\author{
Irfan Navabshan \\ nirfanahamed1985@live.com \\ Balasubramaniyan Sakthivel \\ sakthivelbala.s@gmail.com \\ Rajesh Pandiyan \\ raju19marc@gmail.com \\ Mariya Gover Antoniraj \\ gover.anto@gmail.com \\ Selvakumar Dharmaraj \\ sdharmaraj77@gmail.com; selvakumar@ametuniv.ac.in \\ Veeramuthu Ashokkumar \\ rvashok2008@gmail.com
}

Kuan Shiong Khoo

kuanshiong.khoo@hotmail.com

Kit Wayne Chew

kitwayne.chew@xmu.edu.my

1 Crescent School of Pharmacy, B.S. Abdur Rahman Cresent Institute of Science and Technology, Chennai, India

2 Drug Discovery and Development Research Group, Department of Pharmaceutical Technology, University College of Engineering, Anna University, BIT Campus, Tiruchirapalli, Tamil Nadu 620024, India

3 Centre for Materials Engineering and Regenerative Medicine, Bharath Institute of Higher Education and Research, Chennai 600073, India 
4 Department of Biotechnology, Alagappa University, Karaikudi 630003, India

5 Department of Marine Biotechnology, Academy of Maritime Education and Training [AMET] (Deemed To Be University), Chennai, Tamil Nadu 603112, India

6 Faculty of Science, Center of Excellence in Catalysis for Bioenergy and Renewable Chemicals (CBRC), Chulalongkorn University, Bangkok, Thailand

7 Department of Energy and Environmental Engineering, Saveetha School of Engineering, Saveetha Institute of Medical and Technical Sciences, Saveetha University, Chennai 600077, India
8 Department of Chemical and Environmental Engineering, Faculty of Science and Engineering, University of Nottingham Malaysia, Jalan Broga, 43500 Semenyih, Selangor Darul Ehsan, Malaysia

9 School of Energy and Chemical Engineering, Xiamen University Malaysia, Jalan Sunsuria, Bandar Sunsuria, 43900 Sepang, Selangor, Malaysia

10 Department of Pharmaceutics, SRM College of Pharmacy, SRM Institute of Science and Technology, Kattankulathur 603203, India 